\title{
Synoviolin/Hrd1, an E3 ubiquitin ligase, as a novel pathogenic factor for arthropathy
}

\author{
Tetsuya Amano, ${ }^{1,6}$ Satoshi Yamasaki, ${ }^{1,6}$ Naoko Yagishita, ${ }^{1,6}$ Kaneyuki Tsuchimochi, ${ }^{1,4}$ \\ Hiroshi Shin, ${ }^{3}$ Ko-ichi Kawahara, ${ }^{5}$ Satoko Aratani, ${ }^{1}$ Hidetoshi Fujita, ${ }^{1,3}$ Lei Zhang, ${ }^{1}$ Rie Ikeda, ${ }^{1}$ \\ Ryoji Fujii, ${ }^{1}$ Naoki Miura, ${ }^{5}$ Setsuro Komiya, ${ }^{4}$ Kusuki Nishioka, ${ }^{2}$ Ikuro Maruyama, ${ }^{5}$ \\ Akiyoshi Fukamizu, ${ }^{3}$ and Toshihiro Nakajima ${ }^{1,7}$

\begin{abstract}
${ }^{1}$ Department of Genome Science and ${ }^{2}$ Rheumatology, Immunology and Genetics Program, Institute of Medical Science, St. Marianna University School of Medicine, Kawasaki, Kanagawa 216-8512, Japan; ${ }^{3}$ Institute of Applied Biochemistry and Center for Tsukuba Advanced Research Alliance, University of Tsukuba, Tsukuba, Ibaraki 305-8577, Japan; ${ }^{4}$ Department of Orthopedic Surgery and ${ }^{5}$ Department of Dermatology and Laboratory of Molecular Medicine, Kagoshima University, Faculty
\end{abstract} \\ of Medicine, Kagoshima 890-8520, Japan
}

Rheumatoid arthritis (RA) is one of the most critical articular diseases with synovial hyperplasia followed by impairment of quality of life. However, the mechanism(s) that regulates synovial cell outgrowth is not fully understood. To clarify its mechanism(s), we carried out immunoscreening by using antirheumatoid synovial cell antibody and identified and cloned "Synoviolin/Hrd1", an E3 ubiquitin ligase. Synoviolin/Hrd1 was highly expressed in the rheumatoid synovium, and mice overexpressing this enzyme developed spontaneous arthropathy. Conversely, synoviolin/hrd1 ${ }^{+/-}$mice were resistant to collagen-induced arthritis by enhanced apoptosis of synovial cells. We conclude that Synoviolin/Hrd1 is a novel causative factor for arthropathy by triggering synovial cell outgrowth through its antiapoptotic effects. Our findings provide a new pathogenetic model of RA and suggest that Synoviolin/Hrd1 could be targeted as a therapeutic strategy for RA.

[Keywords: Rheumatoid arthritis; synovial cells; apoptosis; E3 ubiquitin ligase]

Received March 24, 2003; revised version accepted August 4, 2003.

Rheumatoid arthritis (RA) is one of the most common articular diseases with a prevalence of $\sim 1 \%$ worldwide (Harris 1990; Feldmann et al. 1996). The chronic nature of this disease results in progressive joint destruction, which leads to severe locomotive disability and deterioration of quality of life. Although there has been a significant progress in defining its etiology, the exact cause of RA is still poorly understood. Recently, the burden of musculoskeletal diseases on the society has been recognized throughout the world, and RA is defined as one of the most important diseases in the Bone and Joint Decade (http://www.bonejointdecade.org), which was launched by the World Health Organization (WHO) in 2000 to reduce the social and financial costs of musculoskeletal disorders to the society. Therefore, there is a need for the development of radical treatment, as well as treatment of current symptoms.

The clinical features of RA include chronic inflammation of systemic joints associated with overgrowth of

\footnotetext{
${ }^{6}$ These authors contributed equally to this work.

${ }^{7}$ Corresponding author.

E-MAIL nakashit@marianna-u.ac.jp; FAX 81-44-977-9772.

Article published online ahead of print. Article and publication date are at http://www.genesdev.org/cgi/doi/10.1101/gad.1096603.
}

synovial cells, which eventually causes cartilage and bone destruction in the joint (Aarvak and Natvig 2001; Schett et al. 2001). It is thought that inflammation results from activation of the cytokine system regulated by inflammatory cells (Arend 2001). During the course of inflammation, activated macrophages produce tumor necrosis factor- $\alpha$ (TNF $\alpha)$, interleukin (IL)-1, and IL-6. These cytokines, in turn, stimulate the overgrowth of synovial cells to form a mass of synovial tissue, called pannus, which invades the bone and cartilage through osteoclast activation and protease production (Tak and Bresnihan 2000; Hofbauer and Heufelder 2001; Kaneko et al. 2001; Rehman and Lane 2001; Szekanecz and Koch 2001). Because RA is considered an autoimmune disease, medical treatment targeting inflammation has been applied. However, it is reported that TNF $\alpha$ blockade therapy hardly leads to complete remission of the disease, and $\sim 25 \%$ of the patients with RA do not respond to such therapy (Green 2000; Clair 2002). Thus, the pathogenesis of RA cannot be explained in all patients by inflammation only. In other words, it is not clear whether inflammation causes subsequent synovial hyperplasia or whether primary spontaneous synovial cell proliferation leads to inflammation. In any case, there is a general 
agreement that synovial cells play an important role in RA. Based on this concept, we have conducted a series of experiments that focused on synovial cells to elucidate the pathogenic role of these cells in RA. First, we succeeded in cloning rheumatoid synovial cells (RSCs) and found that these cells bear the autonomous proliferation properties similar to "immortalized transformed cells" with aberrant cytokine production in culture (Goto et al. 1987, 1990). Although studying RSCs, our group found that human T-cell leukemia virus type I (HTLV-I), one of the epidemic human retroviruses, is capable of triggering arthropathy, and we proposed that it is a prototype of RA and named it HTLV-I-associated arthropathy (HAAP; Kitajima et al. 1991). Furthermore, we ascertained that tax, a viral transforming gene, causes HAAP, and its product, pp40Tax, could transform synovial cells into RSCs in patients and in its overexpressing mice (Iwakura et al. 1991; Nakajima et al. 1993; Aono et al. 1998). However, expression of pp40Tax is not observed in human RSCs. These data prompted us to determine the functionally equivalent endogenous gene products in RSCs as pp40Tax in HAAP synovial cells.

Therefore, to isolate a specific molecule for RSCs, we performed immunoscreening of human cDNA library of RSCs by using anti-RSCs antibodies. Consequently, we cloned "Synoviolin/Hrd1," an E3 ubiquitin ligase. We purpose targeting Synoviolin/Hrdl as a radical cure of RA in the present study.

\section{Results}

\section{Molecular cloning of synoviolin/hrd1}

To identify RSCs specific molecules, we raised antiRSCs polyclonal antibody by using cultured human synovial cells from 10 patients with RA as the immunogen. Immunohistological analysis using this antibody revealed strong reaction in rheumatoid synovia (Fig. 1A). Western blot analysis using this antibody demonstrated several proteins in RSCs but none in other cell lines, including human embryonic kidney-293T cells and human umbilical vein endothelial cells (Fig. 1B, arrows). Therefore, to identify those RSC-specific proteins, 1 million clones of the expression library derived from human RSCs were screened by the antibody. Such screening resulted in the isolation of 26 positive clones; six clones were fibronectin, and three were laminin. Of the remaining 17 clones, one was a strongly reactive clone containing a $1.8 \mathrm{~kb}$ of unknown sequence. We termed it Synovio-lin based on synoviocyte protein. Synoviolin/Hrd1 contained an open reading frame (ORF) of 225 amino acids; however, the translational start site could not be identified. Thus, 5'-Rapid Amplification of cDNA Ends (RACE) and sequencing were performed, and the contiguous sequence of 3028 bp was verified. Full-length synoviolin/hrd1 cDNA contains an ORF of 616 amino acids, which was presumed to be an $83-\mathrm{kD}$ protein (Fig. 1B). We registered this sequence into the GenBank in 1999 (GenBank accession no. AB024690). Hydrophobic analysis of Synoviolin/Hrd1 showed a putative six trans- membrane domain topologies (Fig. 1C), and motif analysis with a simple modular architecture research tool (SMART; Schultz et al. 2000) revealed the presence of a RING-H2 motif (Fig. 1C). Because proteins with RING finger domain are known to have enzymatic activity similar to E3 ubiquitin ligase (Freemont 2000), we studied whether Synoviolin/Hrdl has such activity. Glutathione S-transferase (GST)-Synoviolin/Hrd1 $\Delta$ TM, the soluble RING-H2 motif containing C-terminal 381 residues, exhibited an auto-ubiquitination activity (Fig. 1D). Moreover, exclusion of E1 or E2 completely inhibited this reaction (Fig. 1D). These results indicate that Synoviolin/Hrd1 is an E1- and E2-dependent E3 ubiquitin ligase. To address the importance of the RING finger domain, we generated RING finger mutants of Synoviolin/Hrd1. Indeed, no ubiquitin ligase activity was noted in these mutants (Fig. 1E). We identified Synoviolin/ Hrd1 as an E3 ubiquitin ligase with a six-transmembrane domain, when considered collectively. In 2002, the same gene was registered as human hrd1 as a homolog of the yeast HRD1 gene (Bays et al. 2001; Kaneko et al. 2002).

\section{Synoviolin/Hrd1 is overexpressed in RSCs}

To confirm the expression of Synoviolin/Hrd1 in synovial tissues, we performed immunohistochemical analysis by using anti-Synoviolin/Hrd1 monoclonal antibody. As expected, marked expression of Synoviolin/Hrd1 was observed in synovial tissues from RA compared with those from patients with osteoarthritis $(\mathrm{OA}$; RA, five cases, OA, five cases; Fig. 1F). Moreover, Western blot analysis revealed that the amount of Synoviolin/Hrd1 protein in cultured synovial cells from RA was greater than that from OA (RA, five cases, OA, five cases; Fig. 1G). We also examined whether the protein expression of Synoviolin/Hrd1 in mouse synovium is affected by collagen-induced arthritis (CIA). As a result, we confirmed the expression of the protein in CIA mice is clearly augmented after the development of CIA by immunohistochemistry by using anti-Synoviolin/Hrd1 antibody (Fig. 1H).

\section{Arthropathy in Synoviolin/Hrd1-overexpressing mice}

It was suggested that Synoviolin/Hrd1 may have certain pathological functions; however, its physiological functions are still unclear. Thus, to investigate the role of this molecule, we first examined the tissue distribution of synoviolin/hrd1 by Northern blot analysis. Mouse synoviolin/hrd1 was ubiquitously expressed in various tissues, with high expression levels in bone, spleen, lung, and testis (Fig. 2A). Next, we established human Synoviolin/Hrd1-overexpressing mice by using a $\beta$-Actin promoter, which drives systemic protein expression (Fig. 2B). Surprisingly, 10 out of 33 Synoviolin/Hrd1-overexpressing mice developed spontaneous arthropathy, with marked joint swelling at 20 wk of age (Fig. 2C). Soft X-ray analysis of the affected joints showed bone destruction (Fig. 2D), and histological analysis of these joints dem- 


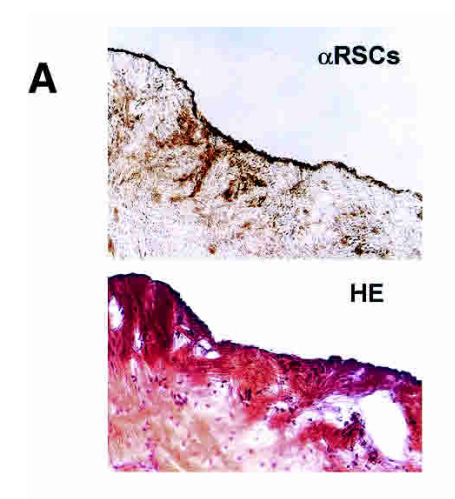

C
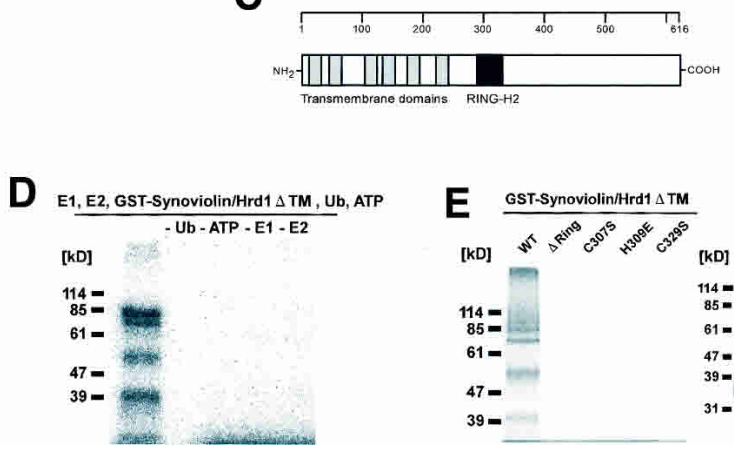

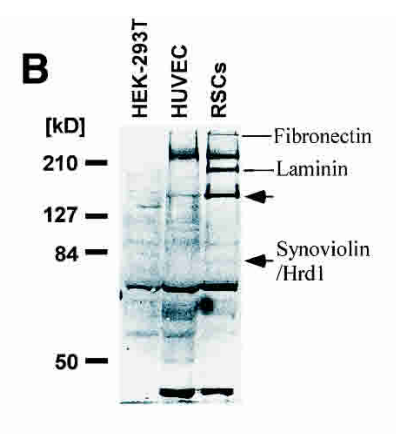

B

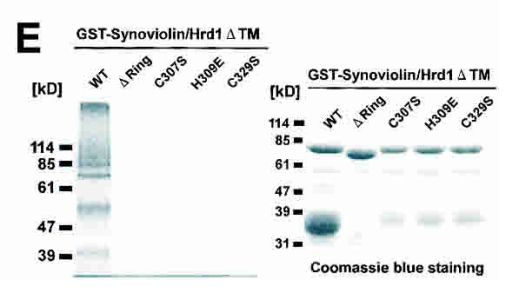

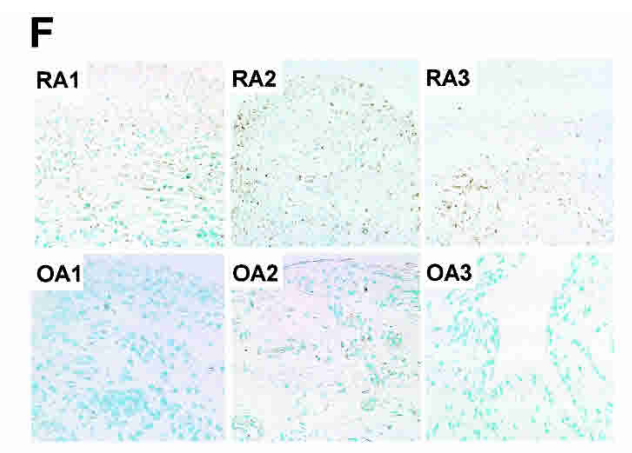

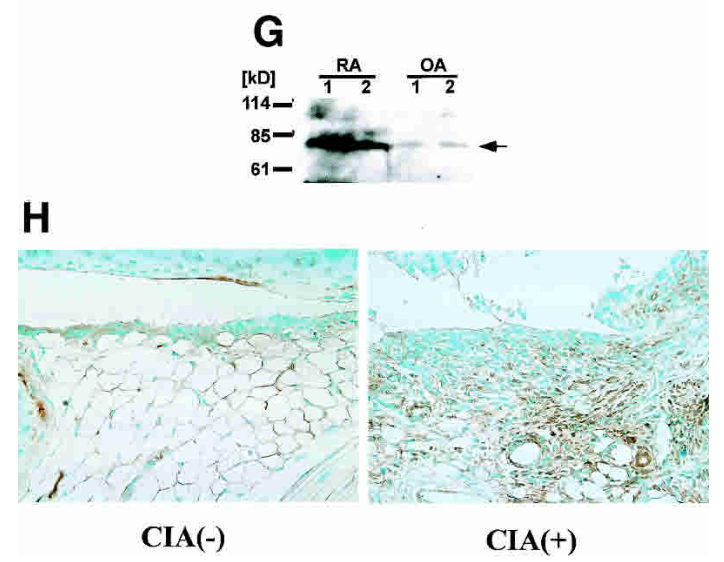

H

Figure 1. Molecular cloning and characterization of Synoviolin/Hrd1. (A, top) Immunostaining of synovial tissue derived from RA patient by anti-RSCs antibody. (Bottom) Hematoxylin and eosin (HE) staining of synovial tissue derived from the same patient. (B) Western blot analysis using anti-RSCs antibody. Arrows show the RSCs-specific bands. Molecular weights of the specific bands are $\sim 140$ and $83 \mathrm{kD}$ from the top. A 83-kD protein was presumed to be Synoviolin/Hrd1. (HEK-293T) Human embryonic kidney-293T cells; (HUVEC) human umbilical vein endothelial cells. $(C)$ Linear arrangement of Synoviolin/Hrd1. The scale above provides amino acid number. $(D)$ E1- and E2-dependent E3 ubiquitin ligase activity of GST-Synoviolin/Hrd1 $\Delta$ TM. Reactions were carried out with removed individual components (e.g., E1, E2). (E, left) Synoviolin/Hrd1 RING finger mutants could not mediate auto-ubiquitination. (Right) GST-Synoviolin/Hrd1 $\Delta$ TM and RING finger mutants were resolved by SDS-PAGE followed by Coomassie blue staining. There are multiple bands for degradation products of GST-Synoviolin/Hrd1 $\Delta$ TM and its mutants. (F) Immunostaining of synovial tissues from RA (top) and OA (bottom) patients by anti-Synoviolin/Hrd1 monoclonal antibody. Representative pictures from RA $(n=5)$ and OA $(n=5)$. $(G)$ Western blot analysis using anti-Synoviolin/Hrd1 monoclonal antibody. Lysates prepared from synovial cells derived from RA and OA patients. Arrow indicates endogenous Synoviolin/Hrd1 protein. Representative pictures from RA $(n=5)$ or OA $(n=5)$. $(H)$ Immunostaining of synovial tissues in knee joint of control (left) and CIA (right) mouse by anti-Synoviolin/Hrd1 monoclonal antibody. Magnification: $A, F, 100 \times$.

onstrated severe synovial cell hyperplasia and bone destruction (Fig. 2E). We also examined the expression of exogenous Synoviolin/Hrd1 protein in the mice by using anti-Flag antibody. The expression of Flag-tagged Synoviolin/Hrd1 was observed in every tissue, including synovial tissue, bone, cartilage, bone marrow, skin, vessels, and adipose tissues (Fig. 2F). These phenotypes of Synoviolin/Hrd1-overexpressing mice exhibited pathological features similar to those of patients with RA. Unexpectedly, there was no other abnormality in these mice throughout their life, apart from the spontaneous arthritis (data not shown).

\section{The synoviolin/ $/ \mathrm{hrd1}^{+/-}$mice are resistant to CIA}

Because overexpressing mice studies, that is, "gain of function," suggest that Synoviolin/Hrd1 acts as an accel- erator/inducer of synovial cell hyperplasia, we attempted to verify this hypothesis in synoviolin/hrd1-deficient mice, that is, "loss of function" (Fig. 3A-D). Mice with CIA are commonly used as a model of experimental arthritis. Specifically, this model shares both immunological and pathological features with human RA; therefore, it has been used as a model to study the pathogenesis of RA and for testing novel therapies. Thus, we considered that this model is suitable for analyzing the function of synoviolin/hrd1 in RA. Because synoviolin/hrd1 homozygous mice $\left(\right.$ syno $\left.^{-/}\right)$died in utero $(\mathrm{N}$. Yagishita, T. Amano, S. Yamasaki, K. Tsuchimochi, H. Shin, K. Kawahara, K. Nishioka, I. Maruyama, A. Fukamizu, and T. Nakajima, in prep.), CIA model was applied to synoviolin/hrd1 heterozygous mice $\left(\right.$ syno $\left.^{+/-}\right)$. The incidence of arthritis in syno ${ }^{+/-}(7 \%, n=27)$ was significantly lower than that of wild-type counterparts $(65 \%, n=23$; Fig. 

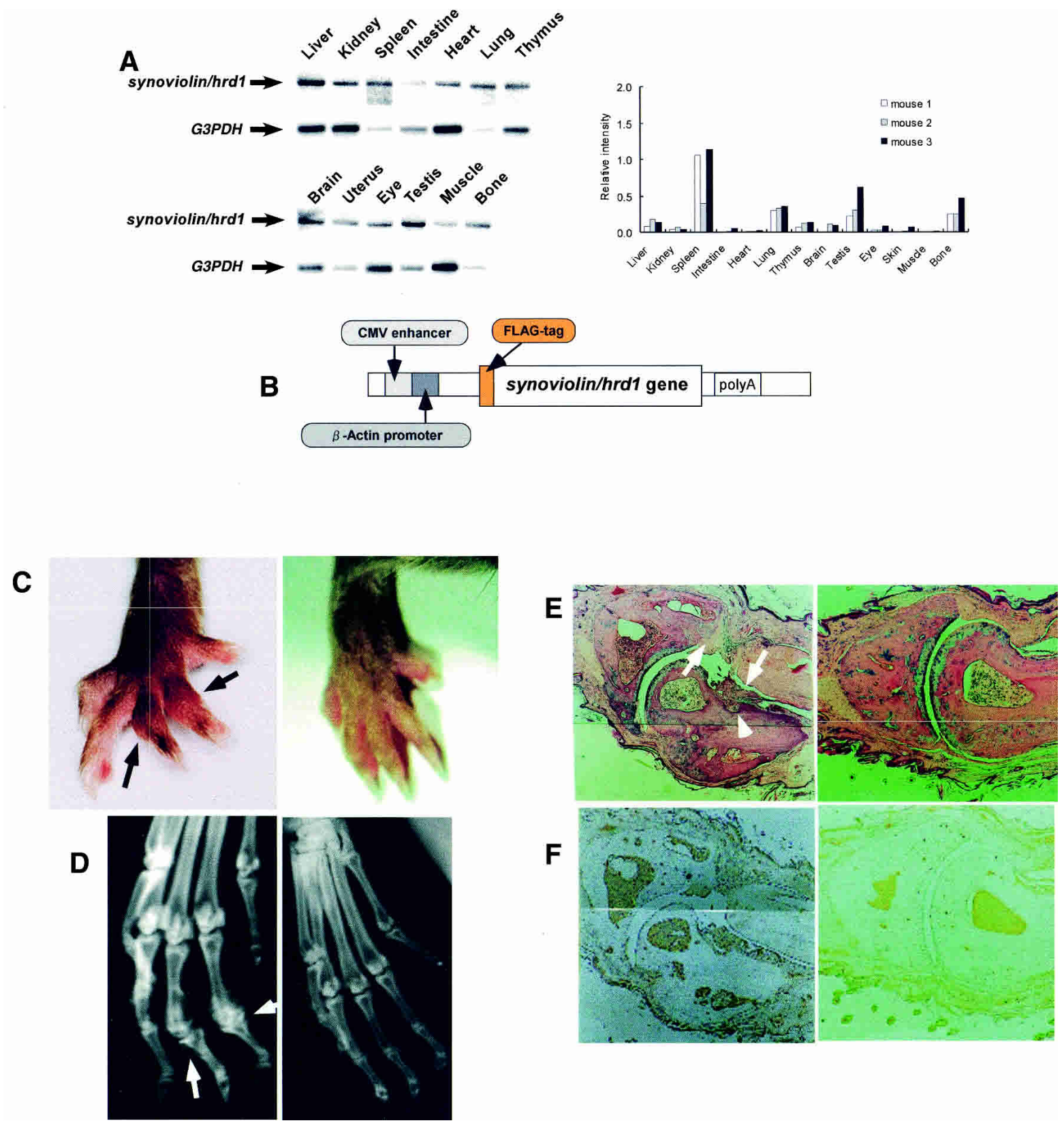

$\mathbf{F}$
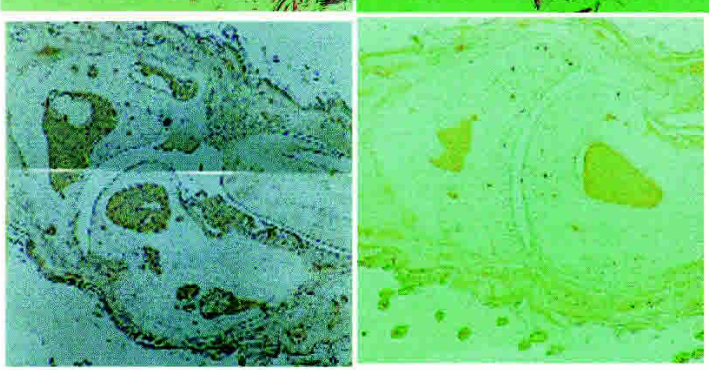

Figure 2. Overexpression of human Synoviolin/Hrd1 in mice causes arthropathy. $(A)$ Northern blot analysis of synoviolin/hrd1. Total RNA was prepared from 7-week-old DBA1/J mice. Fifteen micrograms of total RNA was loaded per lane. Hybridization with G3PDH was used as control. Autoradiographs are shown on the left. The bar graphs on the right show the mRNA expression levels of synoviolin/hrd1 relative to those of G3PDH in mice $(\mathrm{n}=3)$. (B) Schematic representation of human synoviolin/hrd1 transgene for overexpressing mice study. $(C)$ Photograph of the hindlimbs of representative Synoviolin/Hrd1-overexpressing (left) and wild-type (right) mice. Arrows indicate joint swelling. $(D)$ Soft X-ray photographs of hindlimbs of representative Synoviolin/Hrd1-overexpressing (left) and wild-type (right) mice. Arrows indicate bone destruction. (E) Sagittal sections of toe joint from Synoviolin/Hrd1-overexpressing (left) and wild-type (right) mice stained with hematoxylin and eosin. Synovial hyperplasia (arrows) and bone destruction (arrowheads) are evident. Magnification, 100x. (F) Immunostaining of toe joints with anti-Flag antibody (brown) in Synoviolin/Hrd1-overexpressing (left) and wild-type (right) mice. Magnification, 100×.

4A). Furthermore, the arthritis in $s y n o^{+/-}$was less severe than in wild-type mice (Fig. 4A). For instance, swelling and redness were hardly recognized in $s y n o^{+/-}$(Fig. 4B). Moreover, soft X-ray analysis showed no abnormalities of bone and cartilage in syno $^{+/-}$(Fig. 4C).

\section{Apoptosis in syno $^{+/-}$CIA mice}

In CIA model, type II collagen immunization causes a sequence of pathological events including the production of type II collagen antibody, inflammatory cell in- 
Amano et al.

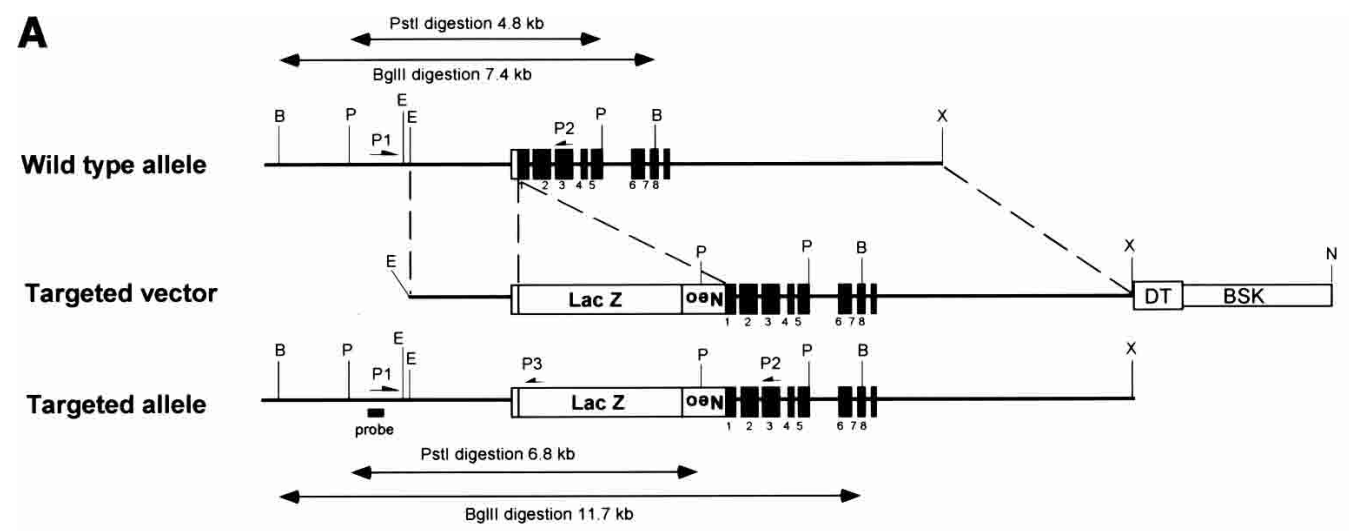

B Digestion with Pst I

Digestion with BgI II
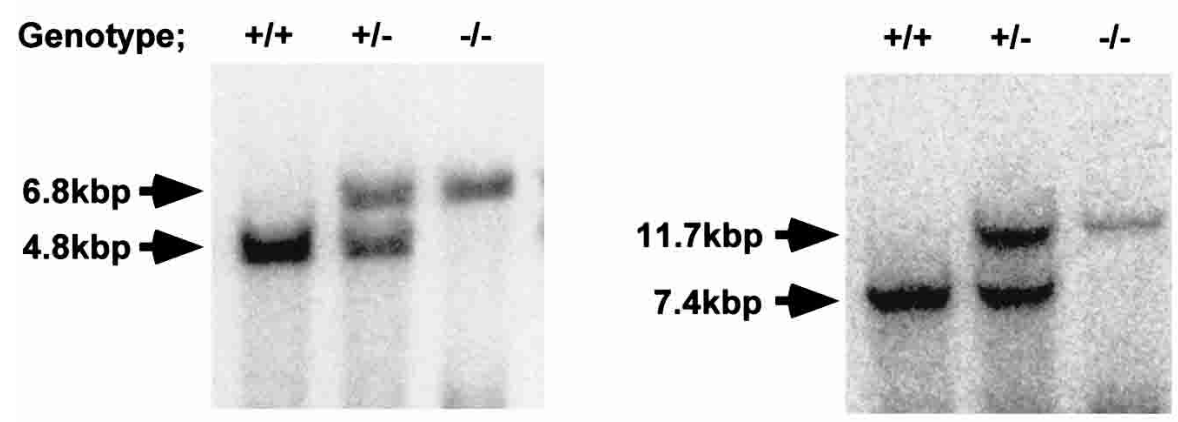

C Genotype; +/+ + +/- - - -

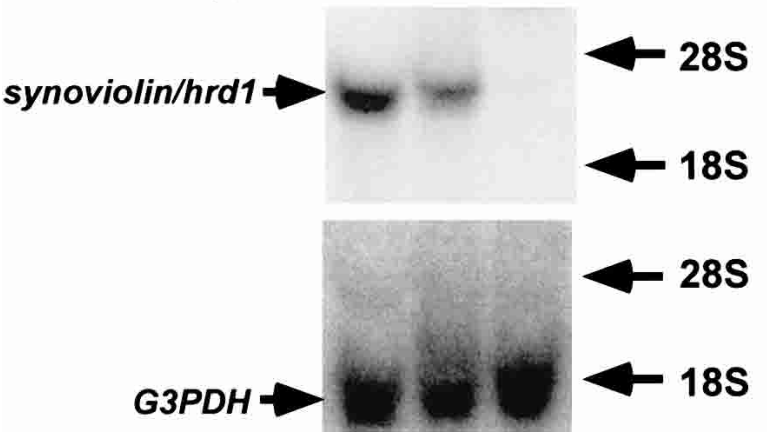

D

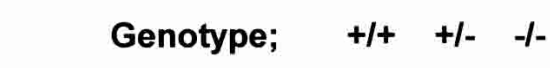

Synoviolin/Hrd1-

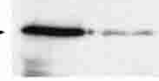

Figure 3. Targeted disruption of the synoviolin/hrd1 gene. (A) Structures of the synoviolin/hrd1 wild-type allele, the targeting vector, targeted allele, and the partial restriction map of the genes before and after targeting events. Exons of the gene are shown as closed boxes, and the $\beta$-galactosidase gene (LacZ), neomycin phosphotransferase gene (Neo), diphtheria toxin- $A$ gene (DT), and pBluescript II (BSK) are shown as open boxes. The restriction sites used are as follows: (B) BglII; (P) PstI; (E) EcoRI; (X) XhoI; and (N) NcoI. (B Southern blot analysis of genomic DNA extracted from E13.0 embryos generated by intercrosses of $s y n o^{+/-}$. The DNA were digested with PstI (left) or BglII (right) and probed with an external probe. $(C)$ Northern blot analysis. Twenty micrograms of total RNA, isolated from E13.0 embryos generated by intercrosses of syno $^{+/-}$, hybridized with the probe for synoviolin/hrd1 or G3PDH probe. (D) The E13.0 embryos total protein was isolated and separated by SDS-PAGE (50 $\mu$ g protein/lane). After transfer of the protein, the membrane was probed with anti-Synoviolin/Hrd1 antibody.

filtration, increase in inflammatory cytokine levels, and synovial cells hyperplasia. In the next step, we verified the involvement of Synoviolin/Hrd1 in each of these processes. First, to investigate whether the reduced incidence of arthritis in $\mathrm{syno}^{+/-}$is due to impairment of antitype II collagen antibody production, we measured the levels of this antibody in the sera. After $3 \mathrm{wk}$ of the second injection, the titer of antibodies was elevated, and the levels were comparable to those of wild type (syno $^{+/-}, 0.70 \pm 0.36 \mathrm{OD}$; wild type, $0.93 \pm 0.44 \mathrm{OD}$; Fig. $5 \mathrm{~A})$. Next, we measured TNF $\alpha$ and IL-1 $\beta$ levels in sera, because these inflammatory cytokines are well known to be elevated in CIA mice and considered as mitogenic factors for synovial cells and known to enhance the overgrowth of these cells. Serum levels of these cytokines were equally elevated in $\mathrm{syno}^{+/-}$and wild-type mice (Fig. 5B). Considered together, these results indicate no impairment of various immune responses to type II colla- 


\section{A}

\begin{tabular}{|c|c|c|c|c|c|c|}
\hline & \multirow[b]{2}{*}{$\mathrm{n}$} & \multirow[b]{2}{*}{0} & \multicolumn{4}{|c|}{ Score (total) } \\
\hline & & & 1 & $2-5$ & $6-10$ & $>10$ \\
\hline $\operatorname{syno}^{+/+}$ & 23 & 8 & 7 & 4 & 2 & 2 \\
\hline synot/- & 27 & 25 & 2 & 0 & 0 & 0 \\
\hline
\end{tabular}

B
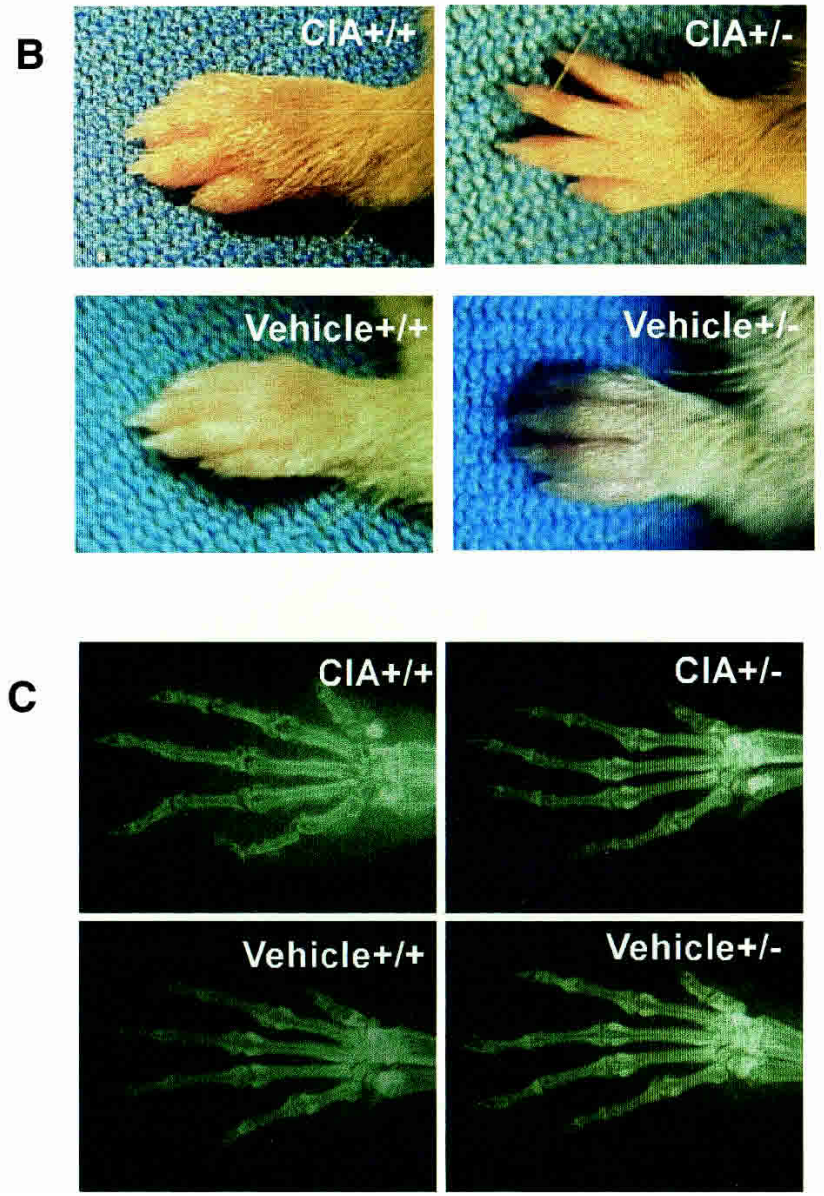

Figure 4. The syno $^{+/-}$are resistant to collagen-induced arthritis. (A) Arthritis score of collagen-induced arthritis in syno $^{+/+}$and syno $^{+/-}$. (B) Photograph of the forelimb in representative CIA-syno ${ }^{+/+}$and CIA-syno ${ }^{+/-}$. Bottom panels show vehicle controls. (C) Soft $\mathrm{X}$-ray photographs of the forelimb of representative CIA-syno ${ }^{+/+}$and CIA-syno ${ }^{+/-}$. Bottom panels show vehicle controls.

gen immunization in the $s y n o^{+/-}$. In other words, the resistance to arthropathy in $\mathrm{syno}^{+/-}$is independent of the immune response. To confirm these results, we applied anticollagen antibody-induced arthritis model to syno $^{+/-}$. As expected, the incidence of arthritis was markedly reduced in syno $^{+-}$(Table 1). Finally, histological analysis showed a significantly low histological arthritis score in syno $^{+/-}$compared with that of wild-type mice (Fig. 5C). Moreover, although inflammatory cell infiltration was observed in syno ${ }^{+/-}$, as in wild-type mice, the subsequent process of advanced synovial cell hyperplasia was hardly detected in syno ${ }^{+-}$(Fig. 5C,D). These results suggest that suppression of synovial cell hyperplasia in syno $^{+/-}$is caused by either reduced cell proliferation or increased apoptosis. To examine whether proliferation is impaired in $\mathrm{syno}^{+/-}$, proliferating cell nuclear antigen (PCNA) staining was performed as a marker for cell proliferation. The number of PCNA-positive cells in syno $^{+/-}$was not different from that in wild-type (percent PCNA-positive cells in syno $^{+/-}$: syno $^{+/+}=2.24 \% \pm 2.63: 1.66 \% \pm 0.73, p=$ 0.73 ; Fig. 5E). These results suggest that repression of synovial cell overgrowth was not caused by reduced proliferation. Next, we tested whether increased apoptosis prevents synovial cell from outgrowth in syno $^{+/-}$. 
Amano et al.

\section{A}

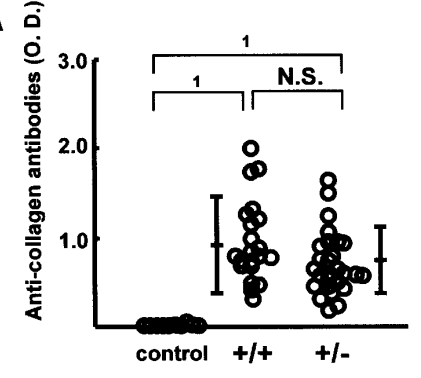

B

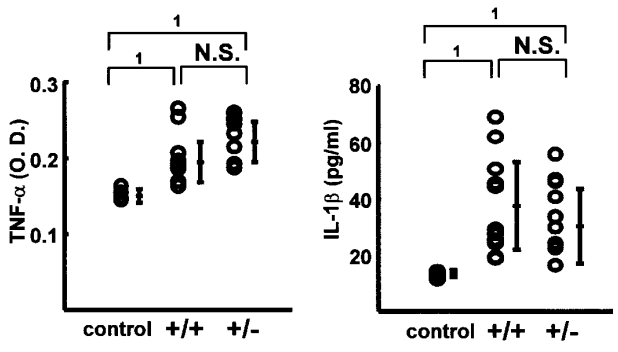

C

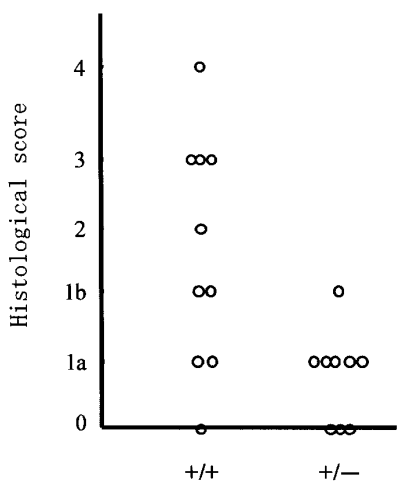

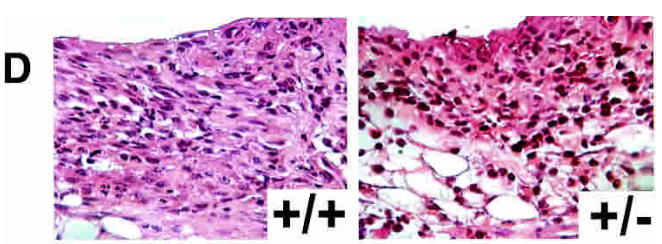

E
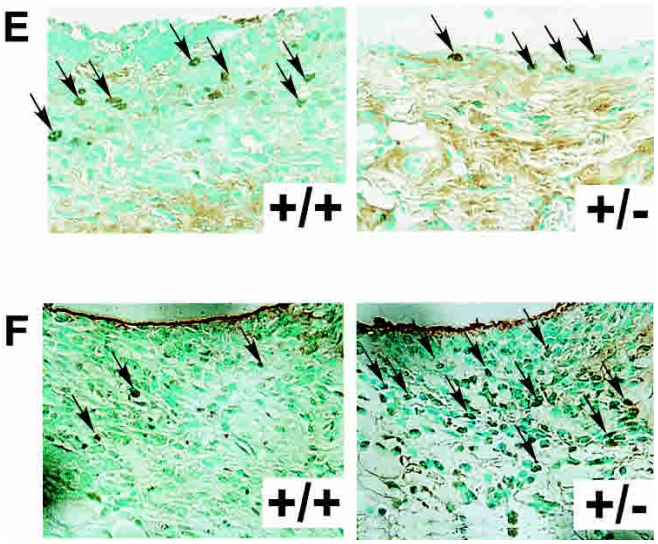

G
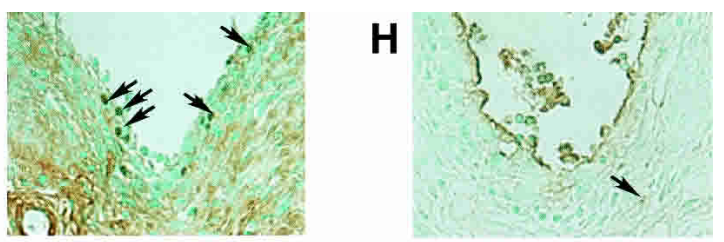

I

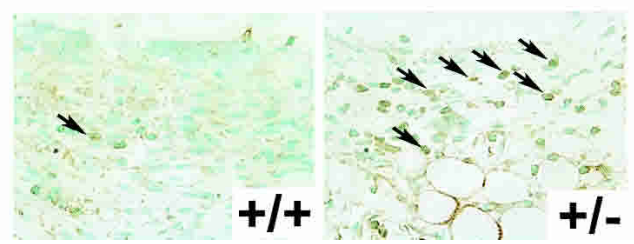

Figure 5. Pathological analysis of collagen-induced arthritis. (A) Serum anti-type II collagen antibody levels in $s y n o^{+/+}$and $s y n o^{+/-}$ were measured by ELISA on day 21 after the second immunization with type II collagen. Data are expressed as mean \pm S.D. (1) $p<0.01$; (N.S.) not significant. (B) Serum TNF $\alpha$ (left) and IL-1 $\beta$ (right) levels were measured by ELISA on day 21 after the second immunization. Data are expressed as mean \pm S.D. (1) $p<0.01$; (N.S.) not significant. (C) Histological arthritis score of collagen-induced arthritis in syno $^{+/+}$and syno $^{+/-}$mice. $(D)$ Sagittal sections of synovia from CIA-syno ${ }^{+/+}$and CIA-syno $o^{+/-}$mice, stained with hematoxylin and eosin. (E) PCNA staining (arrows) of the synovium in CIA-syno ${ }^{+/+}$and CIA-syno ${ }^{+/-}$mice. There is no statistical significance between both groups. $(F)$ TUNEL staining (arrows) of the synovium in CIA-syno ${ }^{+/+}$and CIA-syno ${ }^{+-}$mice. (G) PCNA staining (arrows) of the synovium in Synoviolin/Hrd1-overexpressing mice. (H) TUNEL staining (arrows) of the synovium in Synoviolin/Hrd1-overexpressing mice. (I) ATF6 staining (arrows) of the synovium in $\mathrm{syno}^{+/+}$and $\mathrm{syno}^{+/-}$mice after CIA. Arrows indicate positive nuclear staining of PCNA, TUNEL, or ATF6. Magnification: $D-I, 400 \times$.

Recently, we found that syno ${ }^{-/-}$died in utero due to systemic aberrant apoptosis (N. Yagishita, T. Amano, S. Yamasaki, K. Tsuchimochi, H. Shin, K. Kawahara, K. Nishioka, I. Maruyama, A. Fukamizu, and T. Nakajima, in prep.) In addition, several E3 ubiquitin ligases (e.g., Parkin) are known to exhibit a protective function against endoplasmic reticulum (ER) stress-induced apoptosis (Imai et al. 2000; Kaneko et al. 2002). These studies are consistent with our hypothesis that syno $^{+/-}$are resistant to arthropathy based on the protective effect of apoptosis. To test this, terminal-deoxynucleotidyl
Table 1. Arthritis score in syno ${ }^{+/-}$and wild-type mice with antibody-induced arthritis

\begin{tabular}{lcccccc}
\hline & & \multicolumn{5}{c}{ Score (total) } \\
\cline { 3 - 7 } & $\mathrm{n}$ & 0 & 1 & $2-5$ & $6-10$ & $>10$ \\
\hline syno $^{+/+}$ & 12 & 0 & 0 & 2 & 6 & 4 \\
syno $^{+/-}$ & 15 & 12 & 2 & 1 & 0 & 0 \\
\hline
\end{tabular}

Arthritis score was graded on a 1-4 scale as described in Materials and Methods and was measured $11 \mathrm{~d}$ after lipopolysaccharide injection. 
transferase mediated d-UTP nick end labeling (TUNEL) analysis was performed. The results demonstrated a significant increase of apoptotic cells in CIA-syno ${ }^{+/-}$compared with CIA-wild-type mice (percent TUNEL-positive cells in syno $^{+/-}$: syno $^{+/+}=33.6 \% \pm 1.83: 6.40 \% \pm 1.20$, $p<0.01$; Fig. 5F). No nuclear staining was noted in serial specimens that were not treated with terminal transferase. Considered together, these results suggest that suppression of synovial cell hyperplasia noted in $\mathrm{syno}^{+/-}$is caused by increased apoptosis and not by reduced cell proliferation. We also performed immunohistochemical analysis of PCNA and TUNEL staining in Synoviolin/ Hrd1-overexpressing mice. As a result, we confirmed the presence of PCNA-positive (Fig. 5G) and TUNELpositive (Fig. $5 \mathrm{H}$ ) cells in the synovia of affected mice (Synoviolin/Hrd1-overexpressing mice: PCNA-positive cells $=1.90 \pm 1.22 \%$, TUNEL-positive cells $=3.50 \pm$ $0.81 \%$ ). The percentage of TUNEL-positive cells was slightly but significantly lower in the synovia of Synoviolin/Hrd1-overexpressing mice than in wild-type mice with CIA $(p<0.05)$. However, the percentages of PCNA-positive cells were similar in both groups. Thus, up-regulation of Synoviolin/Hrd1 in Synoviolin/Hrd1overexpressing mice is crucial in preventing apoptosis of synovial cells in the affected joints.

It is well known that E3 ubiquitin ligases including Synoviolin/Hrd1 are crucial in the ER associated degradation (ERAD) system, a process that is indispensable for elimination of unfolded proteins in the ER (Imai et al. 2000; Kaufmann 2002). Several studies reported that disruption of ERAD system causes various human diseases, such as neurodegenerative disease (Imai et al. 2000; Kaufmann 2002). Thus, we postulated that the alternation of ERAD system could cause proliferation or apoptosis of synovial cells (see Fig. 7, below). To test this hypothesis, we examined whether down-regulation of ERAD system indeed takes place in the synovium of CIA-syno ${ }^{+/-}$. Unfortunately, it is impossible to determine the activity of the ERAD system by quantifying the degradation of the yet-unidentified substrate(s) for Synoviolin/Hrd1. Instead, we examined the up-regulation of unfolded protein response (UPR), which is necessary for maintaining a proper protein folding capacity in ER. It is well known that the ERAD and UPR systems are intimately related to each other in ER, and the UPR system is up-regulated in compensation for the loss of ERAD system (Friedlander et al. 2000; Travers et al. 2000). Therefore, we examined the activation of UPR in the synovia of $\mathrm{syno}^{+/-}$treated for induction of CIA by immunohistochemistry using anti-activating transcription factor 6 (ATF6) antibody. The use of this strategy was based on the fact that most of the proteins involved in UPR are transcriptionally activated by nuclear translocation of this ER-resident transcriptional factor. Nuclear translocation of this molecule was significantly increased in the synovia of $\mathrm{syno}^{+/-}$compared with those of syno $^{+/+}$with CIA (percent cells with ATF6 nuclear translocation in syno $^{+/-}:$syno $^{+/+}=35.7 \% \pm 8.3: 8.0 \% \pm 2.0, p$ $<0.01$; Fig. 5I), whereas no translocation of ATF6 was seen in mice without CIA (data not shown). The results indicate that the compensatory activation of UPR is caused by impairment of ERAD system and occurs via ATF6 activation in the joints of $s y n o^{+/-}$with CIA.

Suppression of RSCs growth by synoviolin/hrd1-RNA interference

We concluded that Synoviolin/Hrd1 has antiapoptotic effects in the synovium, and $\mathrm{syno}^{+/-}$is resistant to CIA due to increased apoptosis. To examine whether Synoviolin/Hrd1 contributes to the growth of synovial cells in vitro, RNA interference technique was applied to human RSCs. The effect of duplexes small interfering RNA (siRNA) on Synoviolin/Hrd1 was confirmed by Western blot analysis, which showed a complete repression of Synoviolin/Hrd1 expression in RSCs (Fig. 6A). Furthermore, suppression of Synoviolin/Hrd1 by siRNA completely inhibited the growth of RSCs (Fig. 6B). In addition, under mitogenic stimulation by TNF $\alpha$ and IL-1 $\beta$, the growth of RSCs was inhibited to the level similar to that at no stimulation (Fig. 6B). We also examined whether the down-regulation of Synoviolin/Hrd1 increases the susceptibility to apoptosis caused by disruption of ER function. Synovial cells were cultured in Dulbecco's modified Eagle's medium (DMEM) medium containing $10 \%$ fetal bovine serum (FBS) and $50 \mu \mathrm{g} / \mathrm{mL}$ tunicamycin, which inhibit proper protein folding in ER and promote apoptosis, for $48 \mathrm{~h}$. Apoptosis of synovial cells was determined by TUNEL (control, $5.7 \pm 2.9 \%$; tunicamycin at $50 \mu \mathrm{g} / \mathrm{mL}, 17.7 \pm 3.8 \% ; p<$; Fig. 6 C). In addition, when Synoviolin/Hrd1 was knockdown by treatment with siRNA, synovial cells showed enhanced susceptibility to tunicamycin-induced apoptosis [siRNA for green fluorescent protein (GFP; negative control) and tunicamycin $50 \mu \mathrm{g} / \mathrm{mL}, 26.3 \pm 5.5 \%$; siRNA for Synoviolin/Hrdl and tunicamycin $50 \mu \mathrm{g} / \mathrm{mL}, 66.3 \pm 15.5 \%$; $p<0.05$; Fig. 6C].

\section{Discussion}

Why do synovial cells proliferate abundantly in RA? Although synovial cells are known to play a central role in destroying joints (Szekanecz and Koch 2001), little or no information is available on their cellular characteristics. We hypothesized the involvement of a specific factor in synovial hyperplasia, and accordingly immunoscreened cDNA library derived from human RSCs by using antiRSCs polyclonal antibody. These studies allowed the identification and subsequent cloning of Synoviolin/ Hrd1 (Fig. 1). Structural analysis indicated that Synoviolin/Hrd1 is an E3 ubiquitin ligase with a RING-H2 motif and has a six-transmembrane domain. The role of E3 ubiquitin ligase in the pathogenesis in RA has not yet been elucidated. In the next step, we analyzed the function of Synoviolin/Hrd1 by "gain-of-function" and "lossof-function" strategies. Analysis based on "gain of function," that is, Synoviolin/Hrd1-overexpression mice, showed that $30 \%$ of these mice developed spontaneous 
Amano et al.
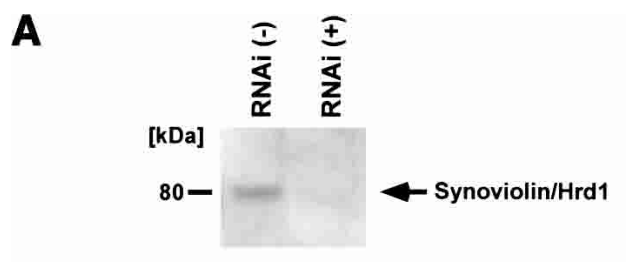

B

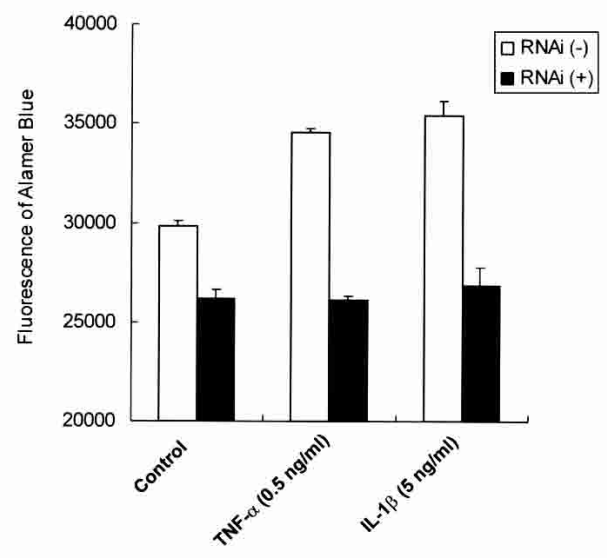

C

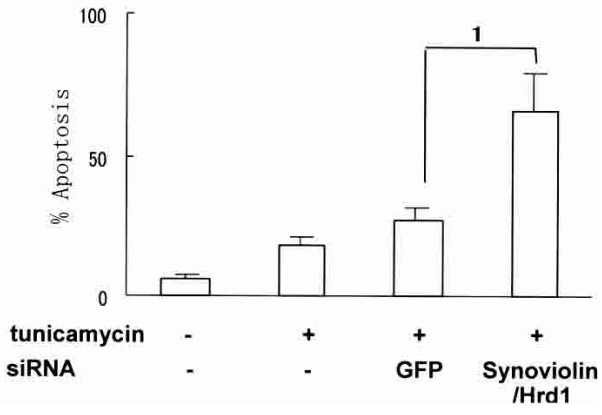

Figure 6. Down-regulation of Synoviolin/Hrd1 expression by siRNA reduces cell growth of RSCs. $(A)$ Western blot analysis of whole-cell extracts from control and siRNA-transfected RSCs by using anti-Synoviolin/Hrdl antibody. (B) RSCs were transfected with siRNA for $3 \mathrm{~d}$ and treated with various cytokines for additional $7 \mathrm{~d}$. Cell growth assays were performed by using Alamar blue. $(C)$ RSCs were transfected with siRNA for $3 \mathrm{~d}$ and treated with tunicamycin for additional $48 \mathrm{~h}$. Apoptotic cells were detected by TUNEL staining, and the percentage of apoptotic cells were presented as mean \pm S.D. (1) $p<0.05$.

arthropathy (Fig. 2B-F). Conversely, analysis based on loss of function, that is, syno ${ }^{+/-}$, demonstrated that these mice were resistant to the development of arthritis (Fig. $4 \mathrm{~A}-\mathrm{C})$, and preliminary, the offspring of crosses between Synoviolin/Hrd1-overexpression mice and syno ${ }^{+/-}$partially rescued arthropathy characteristic of Synoviolin/Hrd1overexpression mice. Taken together, these results indicate that Synoviolin/Hrd1 is essential for the crisis of arthritis. Furthermore, syno ${ }^{+/-}$treated for induction of CIA showed intact immunoreactions but resistance to the development of arthritis, in contrast to the wild type (Figs. 4, 5A,B). Moreover, histological examination showed inflammatory cell infiltration in these mice but lack of advanced synovial cells hyperplasia (Fig. 5C,D). These results suggest that overexpression of Synoviolin/Hrd1 in arthritis may contribute to synovial hyperplasia. This conclusion was confirmed in vitro; synoviolin/hrd1siRNA suppressed the growth of synovial cells even when these cells were stimulated by cytokines (Fig. 6B) and promoted apoptosis induced by disruption of ER function (Fig. 6C). Thus, Synoviolin/Hrd1 targets synovial hyperplasia but not proceeding immunological reactions.

Cell proliferation and apoptosis are two opposite events, and control of this balance is important in homeostasis. Once such balance collapses, it becomes difficult to maintain cellular and/or individual life (Thompson 1995; King and Cidlowski 1998). At the same time, it will lead to an abnormal state, per se, "pathosis," such as cancer (Rudin and Thompson 1997; Evan and Vousden 2001). Applying the same concept to the synovial tissue, and synovial hyperplasia reflects the pathological process of arthritis, it is conceivable that a breakdown of the above balance of cell proliferation and apoptosis has occurred in synovial cells (Pap et al. 2000; Perlman et al. 2001; Pope 2002). In the joints of $s y n o^{+/-}$treated for induction of CIA, although the number of PCNA-positive cells was not different from that of wild type (Fig. 5E), TUNEL-positive cells were significantly higher than in their wild-type counterparts (Fig. 5F). Furthermore, down-regulation of Synoviolin/Hrdl by siRNA suppressed growth of synovial cells (Fig. 6B) and promoted apoptosis induced by disruption of ER function (Fig. 6C). Thus, it could be argued that Synoviolin/Hrd1 overexpression serves as the trigger that leads to the collapse of such balance through its antiapoptotic effect and, consequently, results in synovial hyperplasia.

Apoptosis of synovial cells is indispensable when taking the crisis of RA into consideration (Nakajima et al. 1995; Nishioka et al. 1998). For example, it was reported that the resistance of RSCs to apoptosis is due to upregulation of anti-apoptotic molecules, such as nuclear

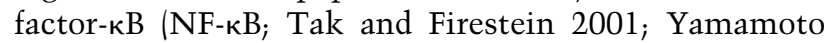
and Gaynor 2001). Therefore, it is reasonable to suggest that Synoviolin/Hrd1 is involved in the pathogenesis of arthritis through its antiapoptotic effect. Our recent study demonstrated that the lack of Synoviolin/Hrd1 in syno $^{-1-}$ was associated with death in utero (N. Yagishita, T. Amano, S. Yamasaki, K. Tsuchimochi, H. Shin, K. Kawahara, K. Nishioka, I. Maruyama, A. Fukamizu, and T. Nakajima, in prep.) caused by enhancement of ER stress-inducible apoptosis. The same study also showed that mouse embryonic fibroblasts from syno ${ }^{-/-}$were selectively susceptible to ER stress-induced apoptosis (N. Yagishita, T. Amano, S. Yamasaki, K. Tsuchimochi, H. Shin, K. Kawahara, K. Nishioka, I. Maruyama, A. Fukamizu, and T. Nakajima, in prep.) In syno $^{+-}$treated for induction of CIA, half of the gene dosage could lead to enhancement of ER stress-induced apoptosis in arthritic joints, and consequently, the animal showed resistance to arthritis (Figs. 4, 5). Indeed, the presence of ER stress in inflamed joints of RA was recently confirmed in human (Fig. 5I; S. Yamasaki, N. Yagishita, T. Amano, K. Tsuchimochi, K. Nishioka, and T, Nakajima, unpubl.). Accordingly, synovial cells of syno ${ }^{+/-}$treated for induc- 
tion of CIA were removed by ER stress, thus preventing synovial cell overgrowth. Taken together, these results indicate the involvement of Synoviolin/Hrd1 in the pathogenesis of arthropathy by attenuating apoptosis mediated by ER stress. Further cellular studies are necessary to identify ER stress mediating signaling in RSCs.

Two biological responses can avoid ER stress, UPR and ERAD (Welihinda et al. 1999; Hampton 2002; Ron 2002). Ubiquitination is the most important process for ERAD system, and various E3 ubiquitin ligases are required for this process (Imai et al. 2000; Kaufman 2002). In fact, Hrd1p, a yeast homolog of Synoviolin/Hrd1, functions as an E3 ubiquitin ligase, which plays a central role in the ERAD system. The ERAD system is important for maintaining cell life (Friedlander et al. 2000). For example, several neurodegenerative diseases, such as polyglutamine disease and autosomal recessive juvenile parkinsonism, are thought to be due to a breakdown of the ERAD system (Imai et al. 2000, 2001; Bence et al. 2001), including ER stress-induced apoptosis. It seems likely that the same mechanism is also operational in resistance of the syno ${ }^{+/-}$to CIA. This conclusion is also based on the results of immunohistological analysis, which indicated disruption of the ERAD system, as reflected by marked up-regulation of the UPR in the mice (Fig. 5I). Therefore, impairment of ERAD system in synovial cells may result in suppression of synovial hyperplasia in human RA. On the other hand, it is conceivable that hyperactivation of the ERAD system by overexpression of Synoviolin/Hrd1 may prevent synovial cell apoptotic death, consequently leading to synovial hyperplasia in RA. Although further studies are needed to define such abnormality, this is the first report that introduces a novel concept for at least certain proliferating diseases, including RA, that is, hyperactivation of the ERAD system (Fig. 7).

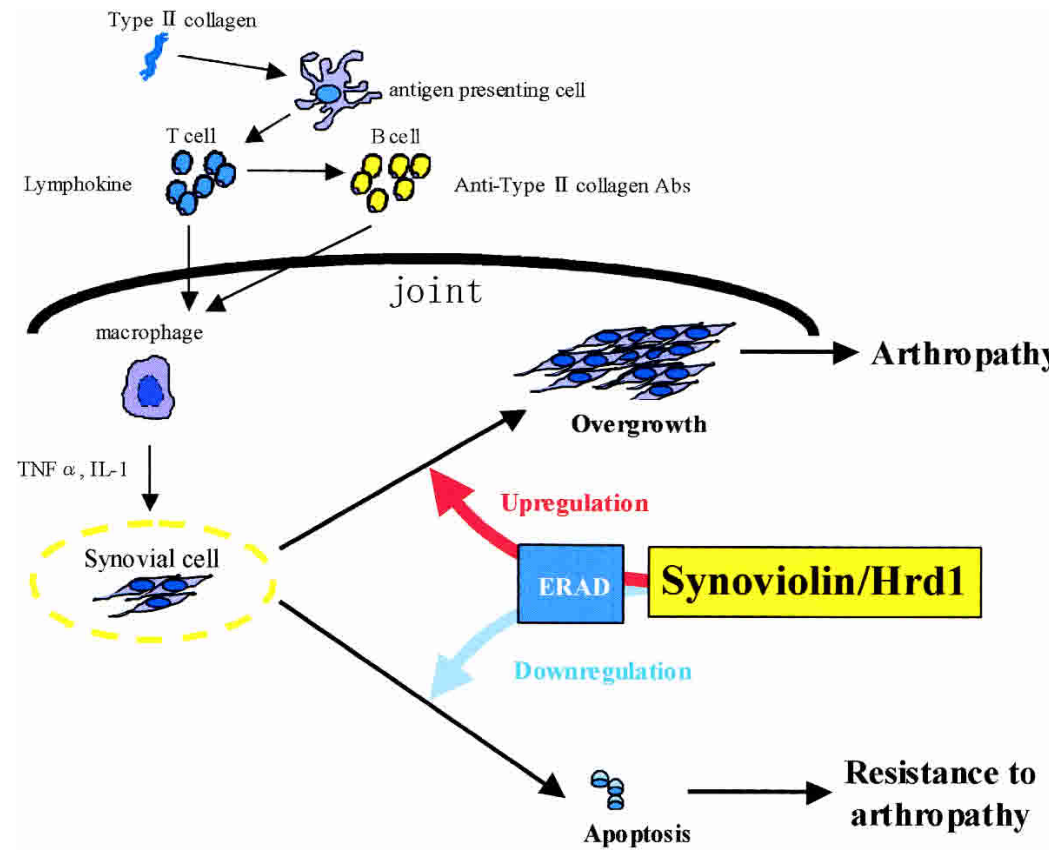

Why do Synoviolin/Hrd1-overexpressing mice show arthropathy only, although such overexpression is generated by using a $\beta$-Actin promoter (Fig. 2B)? Similarly, what causes the disease process in RA to be limited to the joints, although Synoviolin/Hrdl is expressed ubiquitously in all tissues (Fig. 2A)? Although no definite answers can be provided at present, the following three plausible mechanisms might explain these phenomena. First, the amount of Synoviolin/Hrd1 is important. Synoviolin/Hrd1 is highly expressed in both the RA joints (Fig. $1 F, G$ ) and joints of CIA mice (Fig. $1 \mathrm{H})$, and acts as an ubiquitin ligase, leading to arthritis. That is, Synoviolin/ Hrd1 by itself disturbs the balance of cell proliferation and apoptosis through the ERAD system, causing synovial cell hyperplasia. Therefore, identification of the molecule/environmental factor that enhances the expression of Synoviolin/Hrd1 is an important process in the design of effective cure for RA, and we are aiming at this through promoter analysis (K. Tsuchimochi, N. Yagishita, T. Amano, S. Yamasaki, H. Fujita, S. Aratani, K. Nishioka, S. Komiya, and T. Nakajima, unpubl.). Second, the balance between Synoviolin/Hrd1, which functions as an enzyme (an E3 ubiquitin ligase), and its substrate(s) is important. Namely, Synoviolin/Hrdl cannot function as an enzyme in the absence of the substrate(s) in the same environment. Thus, unlike physiological condition, it is conceivable that not only Synoviolin/Hrd1 but also its substrate(s) are highly expressed in synovial cells of RA, which would explain the limited pathology to the joints. It is possible that the substrate(s) is equally expressed in physiological condition and RA. Because Synoviolin/Hrd1 is overexpressed in synovial cells of RA, excessive enzymatic activity could diminish its substrate(s), leading to repression of apoptosis. In this case, a factor that should directly promote apoptosis is assumed as substrate(s). Alternatively, based on the relation with

Figure 7. Role of Synoviolin/Hrdl in collageninduced arthritis. Immunization using type II collagen evokes immunological processes followed by production of anti-type II collagen antibodies, which are thought to result in joint inflammation. Activated macrophages secrete cytokines, such as TNF $\alpha$ and IL-1 $\beta$, which stimulate synovial cell proliferation. Because both antibody and cytokine productions are not impaired in $\mathrm{syno}^{+/-}$, it is conceivable that Synoviolin/Hrd1 is involved in synovial cell overgrowth. Our results indicate that Synoviolin/Hrdl regulates the activity of ERAD system and, consequently, controls synovial cell apoptosis. 
ERAD system, under physiological conditions, cells harboring the substrate(s), which accumulates due to limited activity of Synoviolin/Hrd1, could undergo apoptosis as a result of ER stress. However, in RA, overexpressed Synoviolin/Hrd1 metabolizes its substrate(s) excessively and could circumvent accumulation of substrate(s). Consequently, excessive Synoviolin/Hrd1 suppresses the ER stress/cell death in synovial cells, thus enhancing the opposing process, that is, overgrowth of synoviocytes. In this case, several factors, even those that are expressed broadly, could serve as substrate(s). Considered together, there is a need for further studies to identify Synoviolin/Hrdl substrate(s). In this regard, we are currently conducting such studies using yeast twohybrid system (L. Zhang, R. Ikeda, K. Tsuchimochi, N. Yagishita, T. Amano, S. Yamasaki, H. Fujita, S. Aratani, K. Nishioka, and T. Nakajima, unpubl.).

Third, regulation of Synoviolin/Hrd1 enzymatic activity is important. It is not clear whether the existence of Synoviolin/Hrd1 is directly related to the exhibition of enzymatic activity. It is conceivable that both the activity and expression of Synoviolin/Hrd1 are enhanced in synovial cells in RA. Conversely, its enzymatic activity might not be suppressed under normal physiological conditions despite its expression. In this hypothesis, the function of auto-ubiquitination of Synoviolin/Hrd1 is very interesting (Fig. 1D). For example, it is possible that the activity is regulated by auto-ubiquitination or other forms of posttranslational modification, such as phosphorylation and methylation.

In conclusion, our results demonstrated the importance of Synoviolin/Hrd1 in synovial hyperplasia. Because CIA was almost completely suppressed in $\mathrm{syno}^{+/-}$, future studies should be designed to inhibit the amount and/or activity of Synoviolin/Hrd1 by up to $50 \%$ of that under normal conditions. Our results indicate that Synoviolin/Hrdl is the most advantageous target for arthropathy, and new drugs designed to block Synoviolin/ Hrd1 expression/activity could potentially lead to a radical cure of RA.

\section{Materials and methods}

\section{Preparation of anti-RSCs antibody}

RSCs were established as described previously (Nakajima et al. 1993). The procedure for the preparation of anti-RSCs antibody was essentially the same as described previously (Yokoyama 1991).

\section{Cloning of Synoviolin/Hrd1}

The $\lambda$ ZAP vector (Stratagene) was used to prepare a cDNA library of RSCs according to the instructions provided by the manufacturer. A picoBlue immunoscreening kit (Stratagene) was used for immunoscreening of anti-RSCs. The positive clones were converted to a plasmid pBluescript II SK (+). The base sequence of the DNA inserted into those plasmids was determined with an ABI PRISM 377 DNA Sequencer (Perkin Elmer-Cetus). 5'-RACE method (Frohman et al. 1988) was used to determine the full-length of synoviolin/hrd1 gene.

\section{Anti-Synoviolin/Hrd1 monoclonal antibody}

Anti-Synoviolin/Hrd1 monoclonal antibody was prepared by the standard method (Yokoyama 1991). As an antigen, the peptide sequence (TCRMDVLRASLPAQS) was selected from the domains assumed to have antigenicity.

\section{Northern blot analysis}

Total RNA was isolated from mice tissues by using Isogen (Nippon gene). Total RNA samples $(15 \mu \mathrm{g})$ were denatured with formaldehyde, separated by electrophoresis in $1.0 \%$ agarose, and transferred to nylon filters (Hybond-N, Amersham Pharmacia Biotech). A 1.8-kb fragment of synoviolin/hrd1 cDNA was used as a probe. cDNA was labeled by using the BcaBEST random primer labeling kit (Takara Shuzo Co.) and $\left[\alpha^{-32} \mathrm{P}\right] \mathrm{dCTP}$ (NEN Life Science Products). Hybridization was performed for $12 \mathrm{~h}$ at $42^{\circ} \mathrm{C}$. Filters were washed in $300 \mathrm{mM} \mathrm{NaCl}$ and $30 \mathrm{mM}$ sodium citrate and in $15 \mathrm{mM} \mathrm{NaCl}$ and $1.5 \mathrm{mM}$ sodium citrate at $50^{\circ} \mathrm{C}$. Filters were then exposed to x-ray films by using intensifying screens. A $1.2-\mathrm{kb}$ EcoRI fragment of the glyceraldehyde-3-phosphate dehydrogenase (G3PDH) probe was used as a control.

\section{Western blot analysis}

Cell cultures were harvested and lysed in 1\% NP-40, $25 \mathrm{mM}$ Tris-HCl (pH 6.8), 0.25\% SDS, $0.05 \%$ 2-mercaptoethanol, and $0.1 \%$ glycerol. Aliquots of clear cell lysates were separated on SDS-polyacrylamide gels, transferred onto nitrocellulose membrane, and immunoblotted with anti-Synoviolin/Hrd1 monoclonal antibodies. Bound antibodies were detected by peroxidase-conjugated goat antimouse Igs and ECL detection system (Amersham Pharmacia Biotech).

\section{The ubiquitin ligase activity of Synoviolin/Hrd1}

We used recombinant GST-Synoviolin/Hrd1 $\Delta$ TM and its mutants in for ubiquitination assay. As demonstrated in the photograph of Coomassie blue staining in Figure 1E, there are some degradation products of these proteins. To construct GST-Synoviolin/Hrd1 $\triangle \mathrm{TM}$, cDNA for Synoviolin/Hrd1 fragment corresponding to amino acids 236-616 were cloned into pGEX5X1 (Amersham Pharmacia). Amino acids 291-331 were deleted from Synoviolin/Hrd1 $\Delta \mathrm{TM}$ to generate Synoviolin/Hrd1 $\Delta$ RING. C307S, H309E, and C329S (numbered according to fulllength Synoviolin/Hrd1) Synoviolin/Hrd1 $\Delta$ TM RING finger mutants were generated by PCR-based methods. All plasmids generated by PCR were confirmed by sequence analysis. The procedure for the in vitro ubiquitin ligation assay was essentially the same as described previously (Ohta et al. 1999). Briefly, $40 \mathrm{ng}$ of E1 (Affiniti-Research), $0.3 \mu \mathrm{g}$ of E2 (UbcH5c), $0.75 \mu \mathrm{g}$ of ${ }^{32} \mathrm{P}$-labeled ubiquitin (a gift from T. Ohta), and $1 \mu \mathrm{g}$ of these recombinant proteins were incubated for $30 \mathrm{~min}$ at $37^{\circ} \mathrm{C}$.

\section{Immunohistochemistry}

Immunohistochemistry was performed as described previously (Kawahara et al. 1999). Briefly, articular tissue samples obtained from transgenic mice and RA patients were fixed with $4 \%$ paraformaldehyde in phosphate-buffered saline (PBS). Sections were incubated overnight with anti-RSCs antibody, anti-Synoviolin/ Hrd1 monoclonal antibodies, anti-Flag antibody (anti-Flag M2 monoclonal antibodies, Sigma Chemical Co.), anti-PCNA antibody (Dako), or anti-human ATF6 polyclonal antibody (C-18, Santa Cruz Biotechnology). The specific binding was visu- 
alized by using a diaminobenzidine substrate chromogen system as explained in the manual supplied by the manufacturer (Vector Laboratories). Sections were counterstained by methyl green.

\section{Synoviolin/Hrd1-overexpressing mice}

A vector for overexpression of the human synoviolin/hrd1 gene was constructed by linking a Flag tag to the $5^{\prime}$ side and linking a polyA signal downstream of the $3^{\prime}$ side. The vector was constructed based on pCAGGS (Niwa et al. 1991), then microinjected into the pronuclei of one-cell-stage embryos from BDF1 mice using a standard microinjection procedure (Hogan et al. 1994). To confirm overexpression of human synoviolin/hrd1, genomic DNAs were extracted from the mousetail and used for Southern blot analysis. Synoviolin/Hrd1-overexpressing mice were backcrossed eight times to the DBA/1J and maintained before use.

\section{Generation of synoviolin/hrd1-deficient mice}

The mouse synoviolin/hrd1 locus was cloned from strainC57BL/6 genomic library (Clontech Laboratories) by using a human synoviolin/hrd1 cDNA probe. An NcoI site was created at the translation initiation codon of the gene, and then the NcoI/ $B a m H I$ fragment of the gene was replaced with the LacZ cassette (Saga et al. 1992). The neomycin phosphotransferase (neo) gene cassette derived from pMClneo (Stratagene) was placed downstream of the LacZ gene. The 1.85-kb EcoRI/NcoI fragment and the $8.5-\mathrm{kb}$ Sali/Xhol fragment of the synoviolin/hrd1 gene were included upstream and downstream of these cassettes, respectively. The negative selection with the DT-A cassette was described previously (Yagi et al. 1993a). The TT2 ES cells, derived from an F1 embryo between C57BL/6 and CBA mice, were grown on embryonic fibroblast feeder cells as described previously (Yagi et al. 1993b). Homologous recombination was checked by Southern blot analysis. Two independent syno ${ }^{+/-}$ES clones were injected into ICR 8-cell embryos (Yagi et al. 1993a). Chimeric males with $>80 \%$ agouti coat color were bred to $\mathrm{C} 57 \mathrm{BL} / 6$ or DBAl $/ /$ females, and germ line transmission of the mutant allele was identified by Southern blot analysis of embryo- and tail-derived genomic DNAs. The syno $^{+/-}$were backcrossed eight times to the $\mathrm{DBA} / 1 \mathrm{~J}$ and maintained before use.

\section{Induction of arthritis}

CIA was induced as described previously (Kasama et al. 1995). Briefly, mice were immunized by intradermal injections of 100 $\mu \mathrm{g}$ bovine type II collagen (Collagen Research Center) emulsified in complete Freund's adjuvant (Difco Laboratories). Mice were boosted intradermally with $100 \mu \mathrm{g}$ bovine type II collagen emulsified in incomplete Freund's adjuvant (Difco) at $21 \mathrm{~d}$ after the first immunization. Antibody-induced arthritis was produced by arthritogenic monoclonal antibody cocktail (ImmunoBiological Laboratories), using the instructions provided by the manufacturer. Arthritis score (scale, 1-4) was determined according to the criteria of Hughes et al. (1994), and histological arthritis score was evaluated by the method by Tomita et al. (1999) with some modification: " 0 " indicates normal synovium; " $1 \mathrm{a}$ " indicates cell infiltration without synovial membrane hypertrophy; " $1 b$ " indicates cell infiltration with synovial membrane hypertrophy; " 2 " indicates pannus and cartilage erosion; " 3 " indicates major erosion of cartilage and subchondral bone; and " 4 " indicates loss of joint intergrity and ankylosis, respectively. Histological scoring was conducted in a blinded fashion by two observers (K. Tsuchimochi and S. Yamasaki). Serum levels of TNF $\alpha$ and IL-1 $\beta$ were measured by an enzyme-linked immunosorbent assay (ELISA) kit (Biosource International), and anticollagen antibody levels were measured by ELISA as described previously (Sasai et al. 1999). Briefly, 96-well plates were coated with bovine type II collagen solution $(20 \mu \mathrm{g} / \mathrm{mL})$. Diluted serum samples $(1: 15,000)$ were added for $2 \mathrm{~h}$ at room temperature. Peroxidase-conjugated mouse Igs (Dako) was used as the second antibody. Color development of $o$-phenylendiamine was monitored at $492 \mathrm{~nm}$.

\section{TUNEL assay}

Tissues were dissected and fixed in $4 \%$ paraformaldehyde overnight, dehydrated, embedded in paraffin, and then subjected to TUNEL assay. For in vitro TUNEL assay, cells were collected and plated to slide glasses after being fixed in $4 \%$ paraformaldehyde for $10 \mathrm{~min}$. TUNEL assay was performed according to the protocol provided by the manufacturer (apoptosis in situ detection kit; Wako).

\section{RNA interference assay}

RNA with 21 nucleotides was chemically synthesized (Japan Bio Service). siRNA was carried out based on the protocol of Elbashir et al. (2001). Briefly, $24 \mathrm{~h}$ before transfection, cells in an exponentially growing phase were trypsinized and transferred to a 96-well plate $\left(2 \times 10^{3}\right.$ per well). Transfection was carried out with 100 pmole of siRNA per well by using OligofectAMINE (Invitrogen) according to the instructions provided by the supplier; cells were transfected for $3 \mathrm{~d}$ and treated with IL- $1 \beta$ or TNF $\alpha$ for additional $7 \mathrm{~d}$. To determine the growth of siRNA cells, cell growth assay was performed by using Alamar blue (BioSource International Inc.) according to the instructions provided by the manufacturer.

\section{Statistical analysis}

Data are expressed as mean \pm S.D. Differences between control and treated cells were examined for statistical significance by using the Student's $t$ test. A $P$ value $<0.05$ denoted the presence of a statistically significant difference.

\section{Ethical considerations}

All human and animal experimental protocols described in this study were approved by the Ethics Review Committees of St. Marianna University School of Medicine. Before obtaining human tissues, a signed consent form was obtained from each subject participating in the study.

\section{Acknowledgments}

We thank Dr. T. Ohta for providing plasmids and for the helpful discussions, and M. Suda for instructions on histological analysis. We also thank S. Kato, H. Kawashima, R. Nishimura, M. Noda, H. Takayanagi, S. Tanaka, N. Tsumaki, and H. Yasuda for the helpful discussions, and Dr. M.R. Montminy (The Salk Institute), Dr. R.N. Maini (Imperial College of Science, Technology and Medicine, UK), and T. Hirose for the helpful comments on the manuscript. We are grateful to F. Amano, N. Takagi, A. Sugamiya, S. Shinkawa, H. Sameshima, M. Nakashima, Y. Suzuki, M. Yui, N. Uto, Y. Soejima, and Y. Okamoto for the excellent technical assistance. This study was supported in part by LocomoGene Inc.

The publication costs of this article were defrayed in part by 
payment of page charges. This article must therefore be hereby marked "advertisement" in accordance with 18 USC section 1734 solely to indicate this fact.

\section{References}

Aarvak, T. and Natvig, J.B. 2001. Cell-cell interactions in synovitis: Antigen presenting cells and T cell interaction in rheumatoid arthritis. Arthritis Res. 3: 13-17.

Aono, H., Fujisawa, K., Hasunuma, T., Marriott, S.J., and Nishioka, K. 1998. Extracellular human T cell leukemia virus type I tax protein stimulates the proliferation of human synovial cells. Arthritis Rheum. 41: 1995-2003.

Arend, W.P. 2001. Physiology of cytokine pathways in rheumatoid arthritis. Arthritis Rheum. 45: 101-106.

Bays, N.W., Gardner, R.G., Seelig, L.P., Joazeiro, C.A., and Hampton, R.Y. 2001. Hrd1p/Der3p is a membrane-anchored ubiquitin ligase required for ER-associated degradation. Nat. Cell Biol. 3: 24-29.

Bence, N.F., Sampat, R.M., and Kopito, R.R. 2001. Impairment of the ubiquitin-proteasome system by protein aggregation. Science 292: 1552-1555.

Clair, E.W.S. 2002. Infliximab treatment for rheumatic disease: Clinical and radiological efficacy. Ann. Rheum. Dis. 61 (Suppl II): ii67-ii69.

Elbashir, S.M., Harborth, J., Lendeckel, W., Yalcin, A., Weber, K., and Tuschl, T. 2001. Duplexes of 21-nucleotide RNAs mediate RNA interference in cultured mammalian cells. $\mathrm{Na}$ ture 411: 494-498.

Evan, G.I. and Vousden, K.H. 2001. Proliferation, cell cycle and apoptosis in cancer. Nature 411: 342-348.

Feldmann, M., Brennan, F.M., and Maini, R.N. 1996. Rheumatoid arthritis. Cell 85: 307-310.

Freemont, P.S. 2000. RING for destruction? Curr. Biol. 10: R84R87.

Friedlander, R., Jarosch, E., Urban, J., Volkwein, C., and Sommer, T. 2000. A regulatory link between ER-associated protein degradation and the unfolded-protein response. Nat. Cell Biol. 2: 379-384.

Frohman, M.A., Dush, M.K., and Martin, G.R. 1988. Rapid production of full-length cDNAs from rare transcripts: Amplification using a single gene-specific oligonucleotide primer. Proc. Natl. Acad. Sci. 85: 8998-9002.

Goto, M., Sasano, M., Yamanaka, H., Miyasaka, N., Kamatani, N., Inoue, K., Nishioka, K., and Miyamoto, T. 1987. Spontaneous production of an interleukin 1-like factor by cloned rheumatoid synovial cells in long-term culture. J. Clin. Invest. 80: 786-796.

Goto, M., Okamoto, M., Sasano, M., Yanagisawa, S., Miyamoto, T., Nishioka, K., Nakamura, K., Aotuka, A., Kawakami, N., and Yokohari, R. 1990. Adherent synovial cells from nonrheumatoid arthritis do not release interleukin $1 \beta$ and prostaglandin $\mathrm{E}_{2}$ spontaneously in long term culture. J. Rheumatol. 17: 1299-1302.

Green, G.S. 2000. Etanercept (Enbrel): Update on therapeutic use. Ann. Rheum. Dis. 59 (Suppl I): i46-i49.

Hampton, R.Y. 2002. ER-associated degradation in protein quality control and cellular regulation. Curr. Opin. Cell Biol. 14: 476-482.

Harris, E.D. 1990. Rheumatoid arthritis. Pathophysiology and implications for therapy. New Engl. J. Med. 322: 1277-1289.

Hofbauer, L.C. and Heufelder, A.E. 2001. The role of osteoprotegerin and receptor activator of nuclear factor $\mathrm{\kappa B}$ ligand in the pathogenesis and treatment of rheumatoid arthritis. Arthritis Rheum. 44: 253-259.
Hogan, B., Beddington, R., Constantini, F., and Lacy, E. 1994. Manipulating the mouse embryo. Cold Spring Harbor Laboratory Press, Cold Spring Harbor, NY.

Hughes, C., Wolos, J.A., Giannini, E.H., and Hirsch, R. 1994. Induction of $\mathrm{T}$ helper cell hyporesponsiveness in an experimental model of autoimmunity by using nonmitogenic antiCD3 monoclonal antibody. J. Immunol. 153: 3319-3325.

Imai, Y., Soda, M., and Takahashi, R. 2000. Parkin suppresses unfolded protein stress-induced cell death through its E3 ubiquitin-protein ligase activity. J. Biol. Chem. 275: 3566135664.

Imai, Y., Soda, M., Inoue, H., Hattori, N., Mizuno, Y., and Takahashi, R. 2001. An unfolded putative transmembrane polypeptide, which can lead endoplasmic reticulum stress, is a substrate of Parkin. Cell 105: 891-902.

Iwakura, Y., Tosu, M., Yoshida, E., Takiguchi, M., Sato, K., Kitajima, I., Nishioka, K., Yamamoto, K., Takeda, T., Hatanaka, M., et al. 1991. Induction of inflammatory arthropathy resembling rheumatoid arthritis in mice transgenic for HTLV-I. Science 253: 1026-1028.

Kaneko, M., Tomita, T., Nakase, T., Ohsawa, Y., Seki, H., Takeuchi, E., Takano, H., Shi, K., Takahi, K., Kominami, E., et al. 2001. Expression of proteinases and inflammatory cytokines in subchondral bone regions in the destructive joint of rheumatoid arthritis. Rheumatology 40: 247-255.

Kaneko, M., Ishiguro, M., Niinuma, Y., Uesugi, M., and Nomura, Y. 2002. Human HRD1 protects against ER stressinduced apoptosis through ER-associated degradation. FEBS Lett. 532: 147-152.

Kasama, T., Strieter, R.M., Lukacs, N.W., Lincoln, P.M., Burdick, M.D., and Kunkel, S.L. 1995. Interleukin-10 expression and chemokine regulation during the evolution of murine type II collagen-induced arthritis. J. Clin. Invest. 95: 28682876.

Kaufman, R.J. 2002. Orchestrating the unfolded protein response in health and disease. J. Clin. Invest. 110: 1389-1398.

Kawahara, K., Watanabe, S., Ohshima, T., Soejima, Y., Oishi, T., Aratani, S., Nakata, M., Shibata, M., Inoue, K., Amano, T., et al. 1999. Hypernuclear acetylation in atherosclerotic lesions and activated vascular smooth muscle cells. Biochem. Biophys. Res. Commun. 266: 417-424.

King, K.L. and Cidlowski, J.A. 1998. Cell cycle regulation and apoptosis. Annu. Rev. Physiol. 60: 601-617.

Kitajima, I., Yamamoto, K., Sato, K., Nakajima, Y., Nakajima, T., Maruyama, I., Osame, M., and Nishioka, K. 1991. Detection of human $\mathrm{T}$ cell lymphotropic virus type I proviral DNA and its gene expression in synovial cells in chronic inflammatory arthropathy. J. Clin. Invest. 88: 1315-1322.

Nakajima, T., Aono, H., Hasunuma, T., Yamamoto, K., Maruyama, I., Nosaka, T., Hatanaka, M., and Nishioka, K. 1993. Overgrowth of human synovial cells driven by the human $\mathrm{T}$ cell leukemia virus type I tax gene. J. Clin. Invest. 92: 186-193.

Nakajima, T., Aono, H., Hasunuma, T., Yamamoto, K., Shirai, T., Hirohata, K., and Nishioka, K. 1995. Apoptosis and functional Fas antigen in rheumatoid arthritis synoviocytes. Arthritis. Rheum. 38: 485-491.

Nishioka, K., Hasunuma, T., Kato, T., Sumida, T., and Kobata, T. 1998. Apoptosis in rheumatoid arthritis: A novel pathway in the regulation of synovial tissue. Arthritis Rheum. 41: 1-9.

Niwa, H., Yamamura, K., and Miyazaki, J. 1991. Efficient selection for high-expression transfectants with a novel eukaryotic vector. Gene 108: 193-199.

Ohta, T., Michel, J.J., Schottelius, A.J., and Xiong, Y. 1999. ROC1, a homolog of APC11, represents a family of cullin partners with an associated ubiquitin ligase activity. Mol. Cell 3: 535-541. 
Pap, T., Muller-Ladner, U., Gay, R.E., and Gay, S. 2000. Fibroblast biology: Role of synovial fibroblasts in the pathogenesis of rheumatoid arthritis. Arthritis Res. 2: 361-367.

Perlman, H., Pagliari, L.J., and Volin, M.V. 2001. Regulation of apoptosis and cell cycle activity in rheumatoid arthritis. Curr Mol Med. 1: 597-608.

Pope, R.M. 2002. Apoptosis as a therapeutic tool in rheumatoid arthritis. Nat. Rev. Immunol. 2: 527-535.

Rehman, Q. and Lane, N.E. 2001. Bone loss: Therapeutic approaches for preventing bone loss in inflammatory arthritis. Arthritis Res. 3: 221-227.

Ron, D. 2002. Translational control in the endoplasmic reticulum stress response. J. Clin. Invest. 110: 1383-1388.

Rudin, C.M. and Thompson, C.B. 1997. Apoptosis and disease: Regulation and clinical relevance of programmed cell death. Annu. Rev. Med. 48: 267-281.

Saga, Y., Yagi, T., Ikawa, Y., Sakakura, T., and Aizawa, S. 1992. Mice develop normally without tenascin. Genes \& Dev. 6: 1821-1831.

Sasai, M., Saeki, Y., Ohshima, S., Nishioka, K., Mima, T., Tanaka, T., Katada, Y., Yoshizaki, K., Suemura, M., and Kishimoto, T. 1999. Delayed onset and reduced severity of collagen-induced arthritis in interleukin-6-deficient mice. Arthritis Rheum. 42: 1635-1643.

Schett, G., Tohidast-Akrad, M., Steiner, G., and Smolen, J. 2001. The stressed synovium. Arthritis Res. 3: 80-86.

Schultz, J., Copley, R.R., Doerks, T., Ponting, C.P., and Bork, P. 2000. SMART: A web-based tool for the study of genetically mobile domains. Nucleic Acids Res. 28: 231-234.

Szekanecz, Z. and Koch, A.E. 2001. Update on synovitis. Curr. Rheumatol. Rep. 3: 53-63.

Tak, P.P. and Bresnihan, B. 2000. The pathogenesis and prevention of joint damage in rheumatoid arthritis: Advances from synovial biopsy and tissue analysis. Arthritis Rheum. 43: 2619-2633.

Tak, P.P. and Firestein, G.S. 2001. NF-кB: A key role in inflammatory diseases. J. Clin. Invest. 107: 7-11.

Thompson, C.B. 1995. Apoptosis in the pathogenesis and treatment of disease. Science 267: 1456-1462.

Tomita, T., Takeuchi, E., Tomita, N., Morishita, R., Kaneko, M., Yamamoto, K., Nakase, T., Seki, H., Kato, K., Kaneda, Y., et al. 1999. Suppressed severity of collagen-induced arthritis by in vivo transfection of nuclear factor $\kappa \mathrm{B}$ decoy oligodeoxynucleotides as a gene therapy. Arthritis Rheum. 42: 2532-2542.

Travers, K.J., Patil, C.K., Wodicka, L., Lockhart, D.J., Weissman, J.S., and Walter, P. 2000 Functional and genomic analyses reveal an essential coordination between the unfolded protein response and ER-associated degradation. Cell 101: 249-258.

Welihinda, A.A., Tirasophon, W., and Kaufman, R.J. 1999. The cellular response to protein misfolding in the endoplasmic reticulum. Gene Expr. 7: 293-300.

Yagi, T., Nada, S., Watanabe, N., Tamemoto, H., Kohmura, N., Ikawa, Y., and Aizawa, S. 1993a. A novel negative selection for homologous recombinants using diphtheria toxin A fragment gene. Anal. Biochem. 214: 77-86.

Yagi, T., Tokunaga, T., Furuta, Y., Nada, S., Yoshida, M., Tsukada, T., Saga, Y., Takeda, N., Ikawa, Y., and Aizawa, S. 1993b. A novel ES cell line, TT2, with high germline-differentiating potency. Anal. Biochem. 214: 70-76.

Yamamoto, Y. and Gaynor, R.B. 2001. Therapeutic potential of inhibition of the NF-кB pathway in the treatment of inflammation and cancer. J. Clin. Invest. 107: 135-142.

Yokoyama, W.N. 1991. Current protocol in immunology (ed. J.E. Coligan, et al.), pp. 2.1.1-2.5.17. John Wiley \& Sons, New York, NY. 


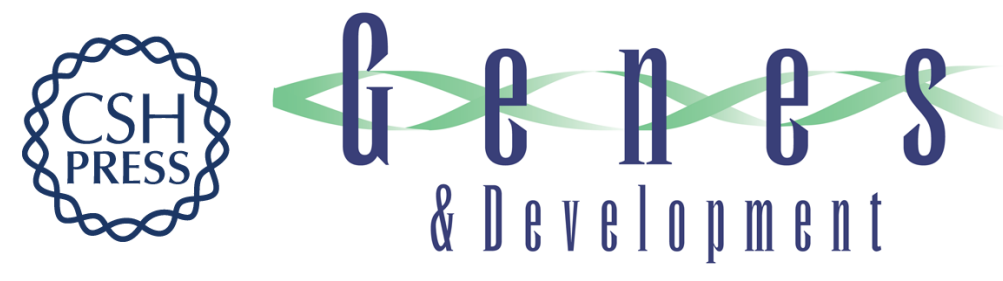

\section{Synoviolin/Hrd1, an E3 ubiquitin ligase, as a novel pathogenic factor for arthropathy}

Tetsuya Amano, Satoshi Yamasaki, Naoko Yagishita, et al.

Genes Dev. 2003, 17:

Access the most recent version at doi:10.1101/gad.1096603

References This article cites 50 articles, 9 of which can be accessed free at: http://genesdev.cshlp.org/content/17/19/2436.full.html\#ref-list-1

License

Email Alerting

Receive free email alerts when new articles cite this article - sign up in the box at the top Service right corner of the article or click here.

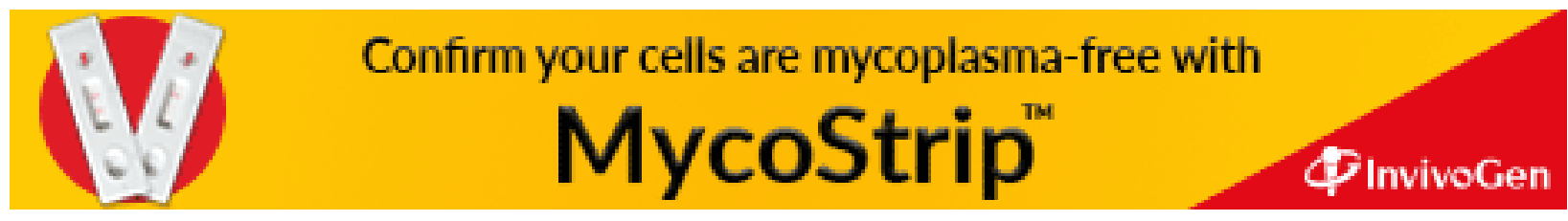

